\title{
A Study of Magnetic Field in the Lung of Workers in an Asbestos Factory
}

\author{
Xing-tai WENG ${ }^{1}$, Jun-cai YAO ${ }^{1)}$, Yue-jian WANG ${ }^{1)}$, \\ Tian-xi $\mathrm{HU}^{2)}$, Zhi-guan $\mathrm{YU}^{2)}$, Zhi-ying $\mathrm{LU}^{2)}$ and Jing-sheng GUO' \\ 1) Department of Automatic Control, Shanghai Jiao Tong University \\ Shanghai 200030, The People's Republic of China \\ 2) Shanghai Institute of Industrial Hygiene and Occupational Disease, \\ Shanghai, The People's Republic of China
}

(Received July 13, 1988 and in revised form November 28, 1988)

\begin{abstract}
Magnetic field at the chest in 93 male workers exposed to asbestos dust in an asbestos products factory in China was studied by local magnetization and flux-gate gradiometry. The average field intensity at 12 measurement points over the anterior chest wall was compared among workers with and without asbestosis and among workers of different working age. The field intensity in workers with asbestosis and those suspected to have asbestosis on the basis of $\mathrm{X}$-ray findings was significantly higher than that in workers without asbestosis. It was also found that the field intensity increased with working age. It is suggested that dynamic measurement of magnetic field in the lung of workers exposed to dust containing ferrimagnetic particles would at least serve as a quantitative method for estimating lung dust loads and be valuable for pneumoconiosis prevention.

Key words : Local magnetization-Flux-gate gradiometry-Remnant magnetic field - Magnetopneumography - Demagnetizer - Asbestosis
\end{abstract}

\section{INTRODUCTION}

The dust inhaled and retained in the lungs of workers may contain ferrimagnetic particles, such as magnetite $\left(\mathrm{Fe}_{3} \mathrm{O}_{4}\right)$, etc. When the thorax is magnetized by a magnetic field of medium intensity (about $10^{2}$ Oersted) for a short time (e.g., several seconds), the remnant magnetic field produced by these particles can be detected by a magnetometer. This represents the magnetic field of the lungs. A magnetopneumograph shows the distribution of this field measured at different points over the chest, and provides a non-invasive physical method that may be used to study the amounts of magnetic dust and the proportion of dust accumulated in the lungs.

Magnetopneumography was first reported by D. Cohen. ${ }^{1)}$ For individuals in the general population, the field intensity of the lungs is rather weak, ranging 
from about $10^{-2} \mathrm{nT}$ (nantotesla) downward, ${ }^{2)}$ and can only be detected by a SQUID (superconducting quantum interference device) gradiometer $^{\text {s) }}$ with spatial discriminability. However, for some kinds of workers occupationally exposed to dust containing relatively higher amounts of magnetic particles, such as welding workers, foundry workers and manufacturers of asbestos products, lung fields are about $10^{-1}-10^{1} \mathrm{nT}^{4-8)}$ and can be measured by a flux-gate gradiometer under low magnetic noise conditions. This less sensitive but simpler instrument is also desirable because of its lower cost and maintance. This approach can therefore be used as a new way of monitoring the amounts of dust accumulated in the lungs of workers due to occupational exposure, and for the diagnosis of pneumoconiosis. In this study, we measured the lung field in 93 workers in an asbestos products factory in order to explore the application of magnetopneumography to industrial hygiene.

\section{METHODS}

The subjects were workers at an asbestos products factory, either actively or passively exposed to dust, and with or without asbestosis. Their types of work included raw asbestos processing, asbestos softening, asbestos combing, asbestos spining, asbestos weaving, asbestos rubber production, machine repair and product transport. The raw material used in this factory contained relatively small amounts of magnetic particles. The localized field produced by a coil with a $6 \times 6 \mathrm{~cm}^{2}$ iron core was used to magnetize separate areas of the lung. This field, normal

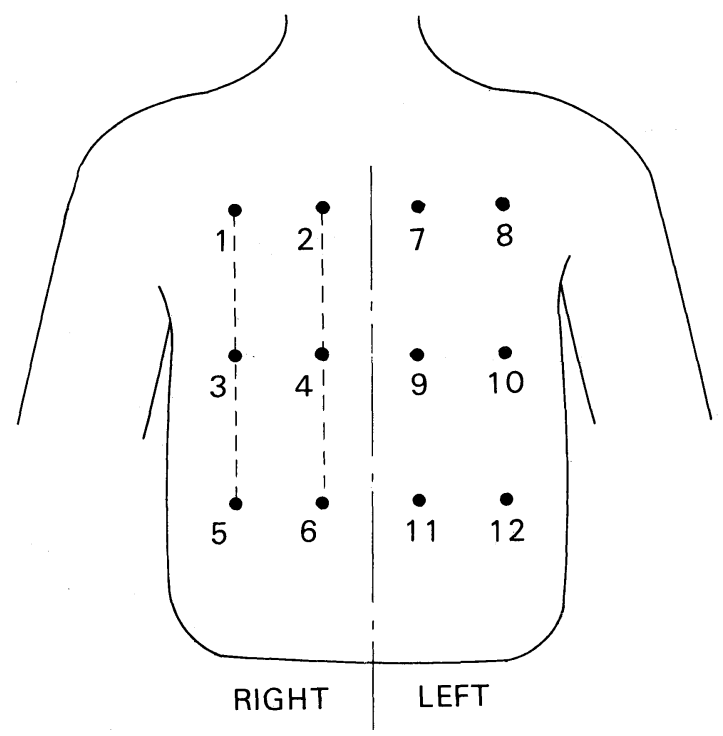

Fig. 1. Location of 12 measurement points. 
to the frontal plane of the chest, was applied for $10 \mathrm{~s}$, being attenuated from $230 \mathrm{mT}$ (millitesla) at the skin to $30 \mathrm{mT}$ at a thoracic depth of $10 \mathrm{~cm}$.

Twelve measurement points were set on the anterior side of the thorax, as shown in Fig. 1. Lines 15 and 26 equally divided the distance between the outer edge of the sternum and the anterior line of the axilla. Points 1 to 6 for the right lung were the intersection points of these lines and the $1 \mathrm{st}, 3 \mathrm{rd}$ and 5 th intercousts. The same applied to points 7-12.

Each subject was stripped to the waist and free from any magnetic articles. The lung region below four neighboring points, such as 1, 2, 4 and 3, was placed in contact with the iron core of a localized field magnetizer and then magnetized by a direct current field. Then, the remnant fields in the lung at these four points were measured one by one with a flux-gate gradiometer. The field intensity normal to the skin at any point was taken by subtracting the reading when this point was near to the probe of the gradiometer $(2 \mathrm{~mm}$ distant $)$ and when the subject moved away from the probe later (about $20 \mathrm{~cm}$ distant). After the lung fields at these four points had been measured, this lung region was demagnetized by the same magnetizer, but now used as demagnetizer carrying an attenuating alternating current. Then, another region of four points 3, 4, 6 and 5 was magnetized, measured and demagnetized. The same procedures were conducted for the left lung.

\section{RESUlts AND Discussion}

The average remnant magnetic fields for different groups classified according to the grade of asbestosis (using Chinese diagnostic criteria*) and activity of the 93 subjects in the asbestos products factory are given in Table 1. Also, the average fields for two lungs in three groups of active workers relative to the degree of asbestosis diagnosed by roentgenogram are shown in Fig. 2.

After processing the field data for two lungs in Table 1, we obtained results for the five groups with different grades of asbestosis and work activity:

1. The differences among the field data for these groups were statistically significant $(\mathrm{F}=31.52, \mathrm{p}<0.01)$.

2. The levels of field for active worker groups-group D with suspected asbestosis, group $\mathrm{C}$ with asbestosis grade $\mathrm{I}$ and group $\mathrm{E}$ with normal roentgenograms-were significantly higher than those for passive groups-group A with asbestosis II and group B with asbestosis I $(\mathrm{p}<0.01)$.

3. Among the active groups, the field levels for groups $C$ and $D$ were statistically higher than that of group $\mathrm{E}(\mathrm{p}<0.01)$, but the difference in field between groups $\mathrm{C}$ and $\mathrm{D}$ was not statistically significant $(\mathrm{p}>0.05)$. Thus, the field values of workers were closely related to their degree of activity. The relatively lower

* This is fundamentally the same as the ILO classification. A detailed comparison of them was published in Ann. Occup. Hyg., 1984; 28: 1-13. 
Table 1. Measured results of lung fields

\begin{tabular}{|c|c|c|c|c|c|c|c|}
\hline & \multirow{2}{*}{ Group } & \multirow{2}{*}{ Number } & \multirow{2}{*}{ Activity } & \multirow{2}{*}{$\begin{array}{l}\text { Average } \\
\text { years of } \\
\text { exposure }\end{array}$} & \multicolumn{3}{|c|}{ Average remnant magnetic field } \\
\hline & & & & & $\begin{array}{c}\text { Right } \\
\text { mean } \pm S E\end{array}$ & $\begin{array}{c}\text { Left } \\
\text { mean } \pm S E\end{array}$ & $\begin{array}{l}\text { Two lungs } \\
\text { mean } \pm \mathrm{SE}\end{array}$ \\
\hline A. & $\begin{array}{r}\text { Asbestosis } \\
\text { grade II }\end{array}$ & 13 & $\begin{array}{l}\text { Retired for more } \\
\text { than } 5 \text { years }\end{array}$ & 24.8 & $.207 \pm .026$ & $.188 \pm .024$ & $.197 \pm .018$ \\
\hline B. & $\begin{array}{l}\text { Asbestosis } \\
\text { grade I }\end{array}$ & 12 & $\begin{array}{l}\text { Changed to be } \\
\text { passive }\end{array}$ & 26.8 & $.163 \pm .015$ & $.108 \pm .013$ & $.135 \pm .010$ \\
\hline C. & $\begin{array}{l}\text { Asbestosis } \\
\text { grade I }\end{array}$ & 12 & Active & 31.3 & $.538 \pm .075$ & $.433 \pm .065$ & $.486 \pm .050$ \\
\hline D. & $\begin{array}{l}\text { Suspected } \\
\text { asbestosis }\end{array}$ & 28 & Active & 22.4 & $.524 \pm .034$ & $.414 \pm .029$ & $.469 \pm .023$ \\
\hline E. & $\begin{array}{l}\text { Normal } \\
\text { roentgeno- } \\
\text { gram }\end{array}$ & 28 & Active & 15.3 & $.436 \pm .030$ & $.352 \pm .025$ & $.394 \pm .020$ \\
\hline
\end{tabular}

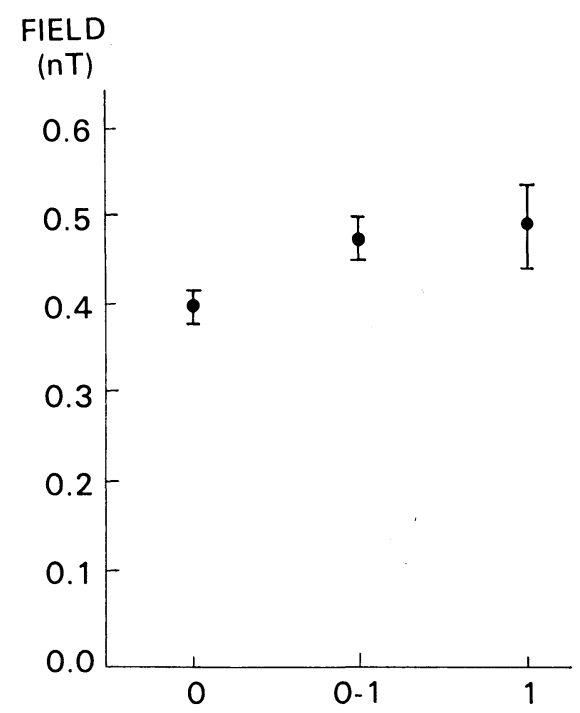

Fig. 2. Average fields of two lungs for groups of active workers versus those with asbestosis.

field values of subjects with asbestosis who ceased to work at dust sites for a certain period (groups A and B) seem to indicate that free dust inhaled into the lungs was continually removed through the respiratory tract, despite the fact that pathological changes were still advancing. From the higher field value in group D with suspected asbestosis compared to that in group $\mathrm{E}$ with normal roentgenograms, it seems worthwhile to further study the value of magnetopneumography for the early diagnosis of asbestosis.

The average fields at each measurement point for these five groups are shown in Fig. 3. It is evident that the field value at each point in the right lung for any 

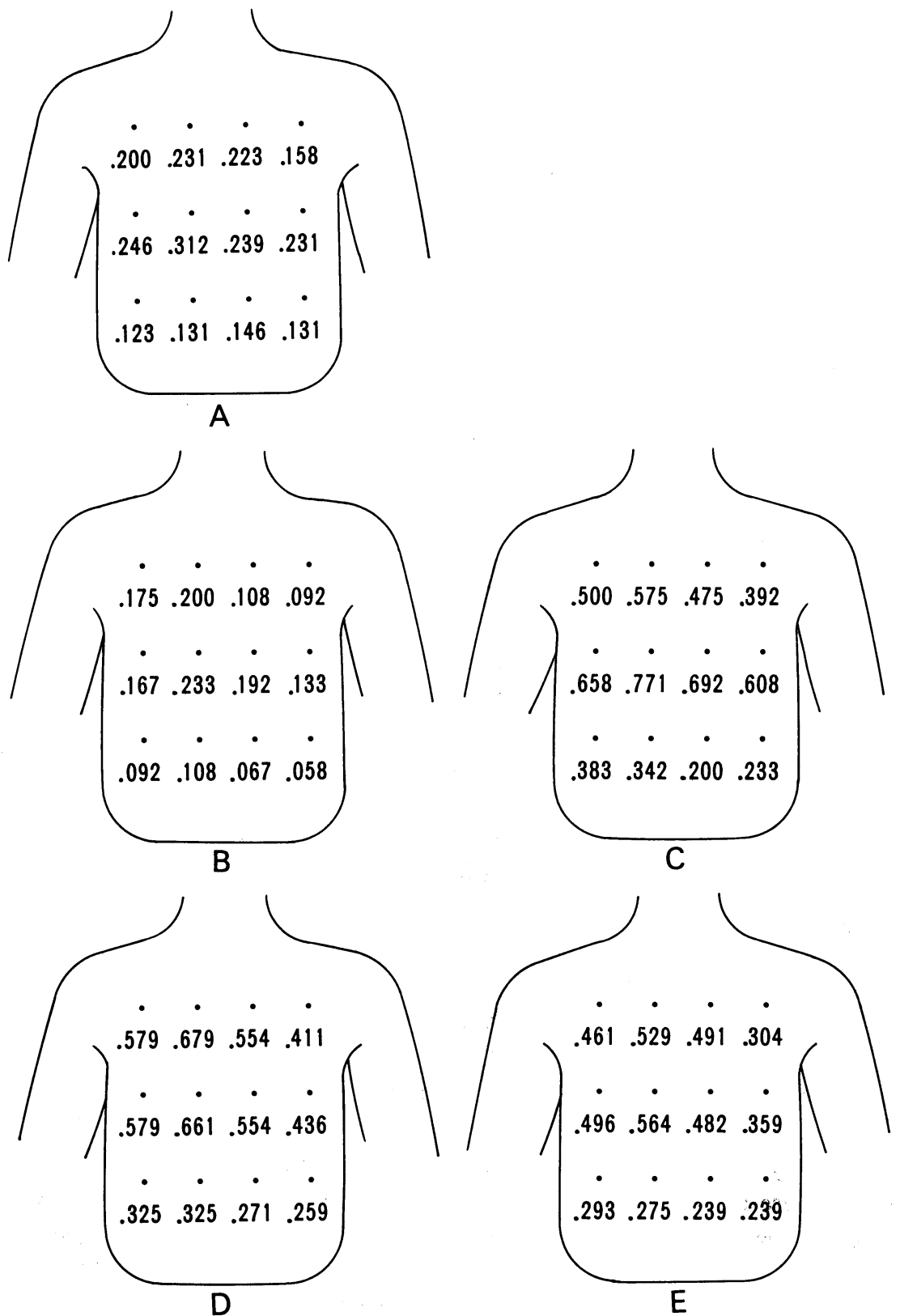

Fig. 3. Average fields at each point for different groups : A-Asbestosis grade II (Retired) B-Asbestosis grade I (Passive) C-Asbestosis grade I (Active) D-Suspected asbestosis (Active) E-Normal roentgenogram (Active) 
Table 2. Average fields for Groups with different nos. of working years

\begin{tabular}{|c|c|c|c|c|c|c|}
\hline \multirow{2}{*}{ Group } & \multirow{2}{*}{$\begin{array}{l}\text { Working } \\
\text { years }\end{array}$} & \multirow{2}{*}{ Number } & \multicolumn{2}{|c|}{ Active } & \multicolumn{2}{|c|}{ Passive } \\
\hline & & & Number & Field (nT) & Number & Field (nT) \\
\hline 1 & $0-10$ & 16 & 14 & 0.435 & 2 & 0.058 \\
\hline 2 & $11-20$ & 22 & 18 & 0.450 & 4 & 0.115 \\
\hline 3 & $21-30$ & 29 & 20 & 0.384 & 9 & 0.246 \\
\hline \multirow[t]{2}{*}{4} & $>31$ & 26 & 16 & 0.509 & 10 & 0.140 \\
\hline & & & \multicolumn{2}{|c|}{$\begin{array}{l}\mathrm{F}=3.03 \\
\mathrm{p}<0.05\end{array}$} & \multicolumn{2}{|c|}{$\begin{array}{l}\mathrm{F}=13.4 \\
\mathrm{p}<0.01\end{array}$} \\
\hline
\end{tabular}

group was greater than that at the corresponding point in the left lung with only a few exceptions; also, the field value at measurement point 4 or 9 (see Fig. 1) was the highest among all points in the right or left lung, respectively. The latter finding indicates that the concentration of magnetic dust in the hilar region is the most dense. As to the higher field value at upper measurement points (e.g., points 1 and 2) in the lung relative to that at corresponding lower points (points 5 and 6), this could be due to the larger measurement distance between the probe and the lung for the lower point.

The average fields for different groups classified according to the number of working years at the dust site and degree of activity of the 93 subjects are given in Table 2. Here, the average fields of the four groups for both active and passive showed a tendency to increase with the number of working years and the field differences for either of the four groups were statistically significant. However, for active cases, group 3 had a lower field than the other three groups, and for passive cases, the field in the group 4 was lower than that in group 3 , but higher than those in groups 1 and 2. This might be due to the complex factors affecting the quantity of dust accumulated in the lungs, such as the concentration of dust at the work sites, personal dust-protective measures and personal ability for respiratory tract clearance, in addition to the number of exposure years.

The above results confirm that magnetopneumography is an effective method for detecting dust accumulated in the lungs of workers due to occupational exposure. It is suggested that the lung fields of workers exposed to dust should be periodically measured and a magnetopneumographic file created for each worker for these dynamic data. These data could be used as a quantitative warning signal of pneumoconiosis risk and as an evaluation index of dust control in a factory when the incidence of this disease is taken into consideration. This approach would be valuable for the prevention of the pneumoconiosis.

From the present data, the magnetic field in the lungs of asbestos workers is considered to be caused by the accumulation of asbestos dust in accordance with occupational history. 


\section{ACKNOWLEDGMENT}

This work was supported by the Coal Ministry of the People's Republic of China.

The authors wish to thank the workers who volunteered for this study, and also their leaders for providing study facilities. Thanks are also extended to Lecturer $\mathrm{Yu}$, Jin-yue for his work at the beginning of this study, and Ms Cao, Mei-fen for typing the manuscript.

\section{REFERENCES}

1. Cohen D. Ferrimagnetic contamination in the lungs and other organs of the human body. Science $1973 ; 180$ : 745-8.

2. Cohen D. Report of the low-field group: The magnetic field of the lung. Nat Tech Inform Service, Tech Rep, Springfield, VA, Pub MIT/FBNML-78/1, 1978: 19.

3. Zimmerman JE. SQUID instrument and shielding for low-level magnetic measurements. J Appl Phy 1977; 48: 702.

4. Kalliomäki PL, Korhonen O, Vaaranen V, et al. Lung retention and clearance of shipyard arc welders. Proc Int Arch Occup Environ Health 1978; 42: 83-90.

5. Kalliomäki PL, Kalliomäki $\mathrm{K}$, Korhonen $\mathrm{O}$, et al. Lung contamination among foundry workers. Proc Int Arch Occup Environ Health 1979; 43: 85-91.

6. Cohen D, Nemoto I. Ferrimagnetic particles in the lung-Part I: The magnetizing process. IEEE Trans Biomed Eng 1984; 31: 261-73.

7. Stroink G, Dahn D, Holland J. Magnetopneumographic estimation of lung dust loads and distribution in asbestos miners and millers. Am Rev Resp Disease 1981; 123: 144.

8. Cohen D, Crowther T, Gibbs T, et al. Magnetic lung measurements in relation to occupational exposure in asbestos miners and millers of Quebec. Env Res 1981; 26: 535-50. 